\title{
POLÍTICA GOVERNAMENTAL DE HABITAÇÃO NO BRASIL: DESAFIOS E PERSPECTIVAS
}

\author{
Andrêza Gomes de Souza ${ }^{1}$ \\ Kássia Nunes da Silva ${ }^{1}$ \\ Michelly de Lourdes Lopes ${ }^{1}$ \\ Renata Rodrigues da Silva ${ }^{1}$
}

\section{Resumo}

A Constituição Federal Brasileira prevê o acesso à habitação como um direito social do cidadão. Entretanto, a realidade vivenciada por milhões de brasileiros, em relação à questão habitacional mostra-se desigual, tendo em vista o déficit habitacional no Brasil, o que demanda a implementação de uma Política Nacional de Habitação (PNH), que garanta à população, sobretudo a de baixa renda, o acesso à moradia digna, promovendo a inclusão social. Destarte, apontam-se como objetivos deste trabalho analisar a circunstância do Brasil no que tange à questão habitacional e ainda, compreender os objetivos da Política Nacional de Habitação $(\mathrm{PNH})$ ressaltando a função dos instrumentos previstos na $\mathrm{PNH}$, tais como: o Sistema Nacional de Habitação, o Subsistema Nacional de Habitação de Interesse Social, o Subsistema Nacional de Habitação de Mercado e o Plano Nacional de Habitação.

Palavras Chaves: Política Nacional de Habitação, infraestrutura urbana, déficit habitacional.

\begin{abstract}
The Federal Constitution provides for access to housing as a social right of the citizen. However, the reality experienced by millions of Brazilians, in relation to the housing issue, it is shown uneven, given the housing deficit in Brazil, which demand the implementation of a National Housing Policy (NHP), which ensures the population, especially low-income, access to decent housing, promoting social inclusion. Thus, it was pointed out as objectives of this study to analyze the condition of Brazil with respect to the housing issue also understand the goals of the National Housing Policy (NHP) emphasizing the role of the tools in PNH, such as

\footnotetext{
${ }^{1}$ Graduandas em Geografia pela Universidade Federal de Uberlândia.

Trabalho apresentado na Disciplina de Planejamento e Gestão Territorial, do curso de Geografia da Universidade Federal de Uberlândia, ministrada pelo Prof. Luiz Gonzaga Falcão Vasconcellos. Emails: andrezgeo@yahoo.com.br, kassianunesdageo@yahoo.com.br, michelly_geo@yahoo.com.br, renatadageo@yahoo.com.br.
} 
the National System Housing Subsystem National Social Housing, Subsystem National Housing Market and the National Housing Plan.

Key Words: National Housing Policy, urban infrastructure, housing deficit

\section{Introdução}

A Constituição Federal Brasileira prevê o acesso à habitação como um direito social do cidadão, garantia que também está prevista na Declaração Universal dos Direitos Humanos, a qual ressalta a todos os cidadãos o direito à moradia digna. Porém, observa-se que a realidade vivenciada por milhões de brasileiros em relação à questão habitacional mostra-se diferente, tendo em vista que o déficit habitacional no Brasil totaliza 7,2 milhões de residências, sendo que 5,5 milhões representam as áreas urbanas e 1,7 milhões são referentes às áreas rurais, segundo informações da Secretaria Nacional de Habitação (SNH). Ainda em relação à carência habitacional, destaca-se que mais de $80 \%$ deste déficit corresponde à parcela da população que possui renda mensal de até cinco salários mínimos, de acordo com a SNH.

Neste sentido, ressalta-se a importância da implementação de uma Política Nacional de Habitação (PNH), que apresenta como principal objetivo garantir à população, sobretudo a de baixa renda, o acesso à moradia digna, promovendo a inclusão social.

Dessa forma, apontam-se como principais objetivos do presente trabalho, analisar a situação do país em relação à questão habitacional, compreender os objetivos da Política Nacional de Habitação e ressaltar a função dos instrumentos previstos na PNH como, por exemplo, o Sistema Nacional de Habitação, o Subsistema Nacional de Habitação de Interesse Social, o Subsistema Nacional de Habitação de Mercado e o Plano Nacional de Habitação.

Para tanto se fez necessário, primeiramente, o levantamento do referencial teórico sobre a temática em questão; posteriormente foram realizadas consultas a instituições federais como, por exemplo, Ministério das Cidades e Secretaria Nacional de Habitação; em seguida foi feito o levantamento de dados referentes à questão habitacional no Brasil, também obtidos em instituições federais; e, finalmente, elaborou-se a redação final.

\section{Histórico das políticas habitacionais do Brasil}

Desde o século XIX, com a demolição dos cortiços, habitados pela população de baixa renda, a questão habitacional constitui-se como um grande problema social do país. Observase que com o decorrer das décadas os problemas relacionados à habitação aumentaram 
consideravelmente, levando à criação de órgãos governamentais voltados exclusivamente para esta questão como, por exemplo, a instituição da Secretaria Nacional de Habitação (SNH). É relevante ressaltar-se também a participação popular como importante instrumento para assegurar melhorias em relação às questões voltadas para a habitação.

No que se refere às políticas habitacionais, destaca-se como primeira política nacional de habitação do Brasil a Fundação da Casa Popular, criada em 1946. Porém, tal programa não se mostrou muito eficaz, apresentando problemas relacionados à falta de recursos para o financiamento, não atendendo o déficit habitacional que já era muito expressivo na década de 1940. As ações da Fundação da Casa Popular também se restringiram a apenas alguns estados do país, contribuindo para o fracasso deste programa.

Já em 1964 institui-se o Banco Nacional de Habitação (BNH), que propôs a criação de um modelo de política habitacional que desde o início apresentou alguns problemas como, por exemplo, a falta de infraestrutura e a distância dos conjuntos habitacionais construídos. Problemas relacionados com a centralização das ações do banco e com o financiamento também foram verificados. Diante dos problemas apresentados, bem como pelo não cumprimento do objetivo principal do BNH de atender a população de baixa renda, em 1986 o mesmo foi extinto.

Após a extinção do $\mathrm{BNH}$, a área da habitação permanece sem recursos financeiros expressivos e sem capacidade institucional de gestão no plano federal. A partir de 1988, com a nova Constituição Federal, a gestão de programas sociais, como a habitação, passa a ser responsabilidade dos estados e municípios, passando a ser observada uma descentralização das políticas habitacionais.

Em 2000, o Instituto Cidadania, uma Organização Não Governamental presidida por Lula da Silva, elaborou o Projeto Moradia. Tal projeto ofereceu sustentação a nova Política Nacional de Habitação, proposta em 2004, e também apresentou propostas para a criação do Ministério das Cidades, em 2003. Apontam-se como principais propostas do Projeto Moradia a ampliação do mercado privado da construção civil para a classe média, tendo em vista que este mercado atendia apenas o segmento de luxo; a concentração dos recursos federais, referentes ao financiamento da habitação, para a parcela da população com renda mensal de até cinco salários mínimos, uma vez que, de acordo com a SNH (2009), entre os anos de 2000 e 2002 , cerca de $60 \%$ dos recursos federais destinados à habitação foram para famílias com renda superior a 5 salários mínimos, que correspondem a cerca de $8 \%$ do déficit habitacional do país. 
Porém, a partir de 2003 a questão habitacional no Brasil ganha novo ímpeto. Com a posse do novo presidente da república, Lula da Silva, em 2003, criou-se o Ministério das Cidades, que abriga a Secretaria Nacional de Habitação, sendo realizada ainda no mesmo ano, a Conferência Nacional das Cidades, que originou a criação do Conselho das Cidades, composto por quatro comitês técnicos, sendo eles: Saneamento Ambiental, Transporte e Mobilidade Urbana, Planejamento Territorial Urbano e Habitação.

Desta forma, a partir da criação do Ministério das Cidades, ocorre em 2004, a elaboração da nova Política Nacional de Habitação, com objetivo principal de garantir à população, principalmente a de baixa renda (até cinco salários mínimos), o direito a moradia digna. Entretanto, apenas a implantação da $\mathrm{PNH}$ não garante o acesso à moradia, e sendo assim, para atender essas necessidades foi elaborado em 2007/2008, o Plano Nacional de Habitação, que tem como meta propor ações e programas que atendam ao perfil das necessidades habitacionais e estabelecer critérios para a alocação regional de recursos, bem como indicar áreas prioritárias para execução dos investimentos.

Ainda em relação aos problemas relacionados ao déficit habitacional do país, ressaltase a insatisfação da população, tendo em vista que a partir da organização de movimentos sociais apoiados pelo Fórum Nacional de Reforma Urbana, criado em 1987, foram elaboradas em 2003 algumas diretrizes para construir uma nova gestão de cidades. Dentre estas diretrizes destaca-se a Diretriz Geral da Política de Habitação, que apresentava como principais objetivos a criação de uma Política Nacional de Habitação e a implantação do Fundo Nacional de Habitação de Interesse Social (FNHIS), sendo ambas as metas atendidas.

O Fundo Nacional de Habitação de Interesse Social bem como o Sistema Nacional de Habitação de Interesse Social resultam da aprovação de um Projeto Lei, primeiro e único projeto de iniciativa popular, que deram origem a Lei $\mathrm{n}^{\circ} 11.204 / 05$, voltada para a questão da habitação de interesse social.

Diante do exposto, observa-se que embora o déficit habitacional do Brasil ainda seja muito expressivo, a partir do ano de 2003 nota-se um empenho maior por parte do governo federal em relação à habitação no país, destacando-se também que a situação ideal ainda está longe de ser alcançada.

\section{A Política Nacional de Habitação}

A Política Nacional de Habitação (PNH) é um documento que sugere algumas propostas que têm como finalidade, garantir o acesso à moradia digna de todo o conjunto da 
população, sobretudo da população de baixa renda, promovendo assim a inclusão social. Para tanto, a política possui alguns componentes essenciais que servem de auxílio para sua implementação, sendo eles: a Integração Urbana de Assentamentos Precários, a Provisão da Habitação e a Integração da Política de Habitação à Política de Desenvolvimento Urbano. Neste sentido, segundo a Secretaria Nacional de Habitação (2004):

A elaboração e implementação da Política obedecem a princípios e diretrizes que têm como principal meta garantir à população, especialmente a de baixa renda, o acesso à habitação digna, e considera fundamental para atingir seus objetivos a integração entre a política habitacional e a Política Nacional de Desenvolvimento Urbano.

A Política Fundiária é responsável por estabelecer as bases das políticas urbanas nos municípios, possibilitando o desenvolvimento de projetos que viabilizem a implantação de programas habitacionais. Sendo assim, cabe à Política Fundiária colocar em prática instrumentos como os Planos Diretores Municipais; promover a regularização fundiária; e ainda, realizar a revisão da legislação urbanística e edilícia, visando proporcionar à população o direito à função social da propriedade urbana, o acesso à terra urbanizada, assim como a ampliação do mercado formal de habitação.

Além disso, a PNH possui alguns instrumentos essenciais para sua viabilização, como o Sistema Nacional de Habitação (SNH); o Desenvolvimento Institucional; o Sistema de Informação, Avaliação e Monitoramento da Habitação; e o Plano Nacional de Habitação (PlanHab).

$\mathrm{O}$ SNH caracteriza-se como o instrumento fundamental da PNH e visa integrar as ações dos governos federal, estadual e municipal com os agentes públicos e privados. Dois subsistemas compõem o SNH, sendo eles: o Subsistema de Habitação de Interesse Social (SHIS) e o Subsistema de Habitação de Mercado (SHM). O Desenvolvimento Institucional visa promover a implantação da PNH de forma descentralizada, por meio de diversos agentes: públicos, privados, sociais e técnicos. O Sistema de Informação, Avaliação e Monitoramento da Habitação tem como objetivo a garantia da revisão periódica da PNH e de seus programas. O PlanHab é o instrumento que vai colocar em prática as propostas apresentadas pela $\mathrm{PNH}$, estabelecendo metas e prazos a partir da priorização das necessidades mais urgentes de acordo com o perfil do déficit habitacional do país. Em função da maior relevância encontrada no SNH e no PlanHab, estes instrumentos serão retratados com maior ênfase no decorrer do trabalho.

Além disso, a PNH busca atingir alguns objetivos como a universalização do acesso à moradia digna, levando em consideração as condições estabelecidas pelo Plano Nacional de 
Habitação e pelo SNH, tais como disponibilidade de recursos e capacidade de produção do setor de construção; promover a urbanização, regularização e inserção dos assentamentos precários à cidade; fortalecer o papel do Estado para obter maior eficácia na administração da PNH; tornar a questão habitacional uma prioridade nacional, promovendo articulação entre os governos federal, estadual, municipal e demais agentes, a fim de potencializar os investimentos e fazer com que estes promovam a manutenção da $\mathrm{PNH}$; democratizar o acesso a terra urbanizada e ao mercado secundário de imóveis; ampliar a produtividade e melhorar a qualidade na produção habitacional; e incentivar a geração de empregos e renda dinamizando a economia, através da mão-de-obra proveniente do setor de construção civil, evitar ao máximo as importações, utilizando produtos nacionais, e contribuir efetivamente com o Produto Interno Bruto (PIB).

\section{A Questão da Habitação}

Conforme já apresentado, a Política Nacional de Habitação foi desenvolvida com o intuito de solucionar os problemas advindos das questões habitacionais de toda a população brasileira, sobretudo entre as famílias de baixa renda do país. Neste sentido, a seguir serão apresentados alguns desses aspectos relacionados à habitação, os quais devem ser enfrentados pela Política no decorrer de sua implementação. Vale ressaltar que as informações que serão apresentadas foram coletadas pelo Censo Demográfico de 2000 e pela Pesquisa de Informações Municipais de 2001, do Instituto Brasileiro de Geografia e Estatística (IBGE).

No que tange ao déficit habitacional quantitativo e qualitativo, o Brasil detém uma carência de aproximadamente 7,2 milhões de moradias, sendo que 5,5 milhões (cerca de 76\%) devem ser construídas nas áreas urbanas e 1,7 milhões (cerca de 23\%) em áreas rurais. Dentre as regiões brasileiras que apresentam maior necessidade de novas habitações, têm-se as regiões Sudeste e Nordeste, uma vez que elas concentram a maior parcela de população urbana do país, representando um déficit de 39,5\% e 32,4\%, respectivamente (IBGE, 2009). Além disso, observa-se uma maior necessidade habitacional, tanto no que se refere à quantidade quanto à qualidade, nas populações urbanas de baixa renda, sobretudo nas Regiões Metropolitanas (RM).

Neste sentido, de acordo com Censo realizado pelo IBGE em 2000, as famílias que possuem renda de até 2 salários mínimos estão tendo cada vez menos acesso à moradia no país. Em contrapartida, percebe-se que a população que detém renda acima de 5 salários mínimos está elevando seu acesso à habitação, o qual passou de um déficit de 15,7\% em 1991 para $11,8 \%$ em 2000. (IBGE, 2009) 
A qualidade dos imóveis no país é outro problema ao qual se deve atenção, visto que é significativa a quantidade de moradias que possuem algum tipo de inadequação, seja no padrão de construção, regularidade fundiária, acesso aos serviços e equipamentos urbanos, dentre outros. Esse perfil demonstra que os programas relacionados à habitação não estão se articulando com os demais programas de desenvolvimento urbano, como a política fundiária, o saneamento ambiental e o programa de infraestrutura urbana. Observa-se ainda, que no Brasil, os problemas relacionados à infraestrutura e saneamento ambiental estão entre os de maior gravidade, visto que 10,2 milhões de habitações no país, isto é, cerca de $32 \%$ do total, possuem alguma carência em sua estrutura (água, esgoto, energia elétrica, coleta de lixo, dentre outros). Esse tipo de deficiência encontra-se principalmente na região Nordeste, onde 4,4 milhões de residências detém algum tipo de problema estrutural, concentrando-se, sobretudo entre a população de baixa renda, que recebe até 3 salários mínimos. (Secretaria Nacional de Habitação, 2009)

De modo geral, tem-se que no Brasil, 83 milhões de pessoas não dispõem de sistema de esgoto e 45 milhões não são atendidas com serviços de água tratada, sendo que, na zona rural há grande escassez destes tipos de serviços, estando ausente de aproximadamente $80 \%$ da população os serviços de água potável e $60 \%$ da população não possuem sistema de esgoto (Secretaria Nacional de Habitação, 2009). Os bolsões de pobreza são onde se encontram os maiores déficits destes serviços e, as regiões Norte e Nordeste lideram o ranking destas carências. As ocupações irregulares no Brasil muitas vezes são excluídas do atendimento desses serviços, devido à dificuldade de acesso a estas localidades, uma vez que a malha viária das cidades nem sempre possui ligação com os locais mais periféricos e distantes da área central.

No que tange às más condições de vida, em função da grande quantidade de pessoas que habitam o mesmo espaço, ocorre em geral, depreciação nas moradias, o que leva a uma contabilização de aproximadamente 837 mil residências no país apresentando este tipo de inadequação, sendo na região Sudeste a maior quantidade de casos encontrados, com cerca de 505.510 moradias depreciadas; em seguida, observa-se a região Nordeste, com 221.782 casos semelhantes (Secretaria Nacional de Habitação, 2009). Entretanto, observa-se uma diferença no tipo de necessidade habitacional entre as regiões do Brasil, dentre as quais o Norte, Nordeste e Centro-Oeste, carecem de melhores condições de infraestrutura e saneamento, uma vez que se percebe a ausência destes serviços em cerca de 50\% dos domicílios destas regiões. Já o Sudeste, devido ao elevado adensamento populacional, necessita de maiores quantidades de habitações para suprir a carência da população que não possui residência regular. 
Em relação à questão fundiária no país, verifica-se a existência de diversas situações de irregularidade, tanto no que se refere às ocupações indevidas de terrenos do setor público e privado, bem como a existência de loteamentos que não estão devidamente regularizados nos órgãos públicos. De acordo com as pesquisas realizadas pelo IBGE (2001), havia irregularidades fundiárias em todas as cidades que apresentavam população acima de 500.000 habitantes e, de acordo com as informações, a tendência é que estas irregularidades se elevem concomitantemente ao crescimento das cidades.

O modo como foi estruturada a urbanização brasileira não se mostra adequada aos padrões de vida local, visto que, promove a especulação imobiliária das áreas centrais, elevando o valor dos terrenos e imóveis, fazendo com que a população de baixa renda não tenha acesso à moradia nestas áreas. Sendo assim, essa população é obrigada a se deslocar para áreas mais distantes do centro, aumentando a expansão horizontal das cidades e estimulando, assim, a constituição de assentamentos precários e muitas vezes irregulares, como as favelas. Neste sentido, tendo em vista que o planejamento urbano, a gestão do solo e a regulação urbanística priorizam o mercado das classes médias em detrimento do mercado de baixa renda, observa-se, portanto, sobretudo nas grandes cidades, um intenso processo de segregação social e exclusão da população menos favorecida economicamente.

No que se refere aos processos de regularização fundiária de assentamentos, dificilmente estes processos chegam à etapa final, em função de uma série de burocracias em que são submetidos e, devido ao grande número de instituições que estão envolvidas no procedimento, como cartórios, poder judiciário e entidades federativas.

A especulação imobiliária criada no país, além de promover a constituição de novos bairros nas zonas periféricas da cidade, provocou também o esvaziamento populacional das áreas centrais, modificando assim sua dinâmica de atividade, passando a concentrar mais as atividades de cunho comercial. Neste contexto, os dados comprovam que, com o passar do tempo, está havendo um aumento do número de domicílios vagos no país, tendo se elevado em 55\% no período de 1991 a 2000. Do total de 4,6 milhões de domicílios vagos no ano de 2000, 49\% estavam concentrados nas zonas metropolitanas e centrais, e 33\% nas zonas rurais (Secretaria Nacional de Habitação, 2009). De acordo com as pesquisas, as RM do Sudeste possuem quantidade de domicílios vagos superior às suas necessidades habitacionais, no entanto, estes imóveis não estão necessariamente adequados, no que tange a sua estrutura, para receber tal população.

A questão da locação de imóveis no país é outro problema que deve ser levado em consideração pelas autoridades governamentais. Segundo informações do IBGE (2001), 
aproximadamente 21 milhões de brasileiros (17\% dos domicílios do país) vivem em imóveis alugados, destinando cerca de $30 \%$ da renda familiar para efetuar o pagamento do mesmo. Observa-se também um crescimento do número de imóveis alugados nas favelas, o que, por um lado demonstra certa capacidade econômica para pagamento de mensalidades do aluguel da população de mais baixa renda, mesmo que seja em locais mais precários, porém, por outro lado, percebe-se que o mercado de locação não conseguiu implementar medidas para equilibrar a oferta de domicílios vagos com a demanda necessária. Já as habitações coletivas que são alugadas pela população de baixa renda (cortiços), não são contabilizadas pelo senso realizado pelo IBGE e, por isso, não se tem informações reais sobre a quantidade nem a qualidade dessas moradias no país.

Assim, como foi mencionado anteriormente, o processo de urbanização brasileiro desenvolvido pelo poder público não se mostra adequado, visto que provoca a formação de vazios urbanos nas áreas centrais e uma intensa segregação e exclusão da população de baixa renda nas zonas periféricas. Esses núcleos urbanos que se formam nas extremidades da cidade dificultam o acesso dos serviços e equipamentos urbanos, reproduzindo ainda mais as desigualdades sócio-territoriais. O transporte coletivo é um exemplo, pois a dificuldade de acesso a esses núcleos urbanos, em função da distância destes com o centro demanda maior tempo nas viagens, além de elevar o valor da passagem. As conseqüências disso são a queda na qualidade do sistema de transporte urbano, juntamente com a redução na qualidade de vida da população.

Ao se falar de assentamentos precários, não se pode deixar de mencionar que a sua demanda tem crescido no país, uma vez que o mercado imobiliário tem limitado a oferta de moradias às classes de baixa renda. Isso ocorre porque o mercado tem voltado seus negócios para atender os interesses das classes média e alta, deixando, portando de construir habitações que priorizem o acesso das populações mais pobres. Nesta conjuntura, o resultado encontrado nas pesquisas é que as favelas tem tido taxas de crescimento superiores às taxas de crescimentos dos domicílios regulares, demonstrando a seguinte realidade: no período de 1991 a 2000 as favelas cresceram 4,18\% ao ano enquanto que os demais domicílios do país obtiveram uma taxa de crescimento anual de $2,8 \%$. Segundo o IBGE, havia no Brasil no ano de 2000 um total de 1.644.266 domicílios favelados. (IBGE, 2009)

O crescimento desordenado das ocupações informais evidencia que esta tem sido a única solução encontrada pela população de baixa renda para ter acesso à moradia e, além disso, comprova também a baixa eficiência das políticas públicas habitacionais de solucionar os problemas do acesso a terra e a moradia, sobretudo no que tange à população carente. 


\section{Sistema Nacional de Habitação (SNH)}

Ao se tratar da Política Nacional da Habitação, é imprescindível que seja abordado o Sistema Nacional de Habitação (SNH), um dos principais instrumentos da referida Política Nacional. O SNH surge com o objetivo de garantir que os recursos públicos sejam, de fato, destinados a população de baixa renda, objetivo que sempre se buscou, mas que quase nunca foi alcançado. O SNH possui uma instância de controle e gestão, da qual fazem parte, além do Ministério das Cidades, o Conselho das Cidades, o Conselho Gestor do Fundo Nacional de Habitação de Interesse Social, Conselhos Estaduais, Municipais e do DF. Além destes, o Fundo Nacional de Habitação de Interesse Social (FNHIS) e os Fundos Estaduais e Municipais de Habitação e Interesse Social, juntamente a agentes financeiros, promotores e técnicos. Toda essa rede de componentes são responsáveis por viabilizar a implementação da Política Nacional de Habitação, através do cumprimento de suas competências específicas.

Vale destacar, além disso, os dois Subsistemas que compõe o SNH, sendo eles o de Habitação de Interesse Social (SHIS) e o de Habitação de Mercado (SHM). Esses subsistemas têm como objetivo comum, dividir as fontes de recursos para que as diferentes características de perfil social sejam atendidas de maneira satisfatória e justa, viabilizando o acesso à moradia digna. Como objetivos específicos, o SHIS objetiva, segundo a Secretaria Nacional de Habitação, "garantir que os recursos públicos sejam destinados exclusivamente a subsidiar a população de mais baixa renda, onde se concentra a maior parte do déficit habitacional brasileiro." Ainda segundo o mesmo documento, o objetivo principal do SHM seria "reorganizar o mercado privado da habitação, tanto na ampliação das formas de captação de

recursos, quanto no estimulo à inclusão dos novos agentes, facilitando a promoção imobiliária (...)".

Tais subsistemas atuam de forma complementar, buscando atingir a universalidade de atendimento, de acordo com dados que são obtidos das diferentes regiões do Brasil. Esses dados permitem uma definição de faixas de atendimento, que indicam como os recursos devem ser aplicados de acordo com as especificidades de cada localidade, considerando variações de custos de produção de habitação e capacidade de pagamento das populações pela mesma. Para isso, o SNH prevê a participação dos três níveis de governo e de agentes públicos e privados que facilitam a concretização do objetivo proposto, o que caracteriza o Sistema como sendo descentralizado.

\section{Plano Nacional de Habitação (PlanHab)}


Tido como um dos instrumentos da Política Nacional de Habitação, o Plano Nacional de Habitação (PlanHab), criado em Março de 2008, é um instrumento de articulação, onde serão apresentadas propostas de estratégias para enfrentar o problema de déficit habitacional e da situação de precariedade e irregularidade das moradias. Dessa forma, objetiva planejar as ações públicas e privadas a fim de melhor direcionar os recursos existentes e aqueles a serem mobilizados para o enfrentamento das necessidades habitacionais do país.

Para isso, o PlanHab é responsável por articular e potencializar os programas e ações dos três níveis de governo e as capacidades existentes dos demais agentes sociais relacionados ao setor da habitação. Assim, é o PlanHab, em seu momento de elaboração, que irá realizar o debate sobre as condições de moradia e as prioridades de intervenção no território, proporcionando, ainda, a produção de dados sobre as necessidades sociais na área da habitação no Brasil. Neste sentido, o Plano deverá, segundo a Secretaria Nacional da Habitação, sugerir ações e programas que estejam adequados ao perfil das necessidades habitacionais do país, além de definir critérios para a distribuição regional dos recursos, indicando as áreas que apresentam maior urgência em receber os investimentos.

A fim de que haja um cumprimento efetivo do Plano, todos os agentes envolvidos na PNH devem estar empenhados nesse sentido, cabendo, mais especificamente, ao Ministério das Cidades, a coordenação da elaboração do Plano Nacional, apoiando a elaboração dos Planos Estaduais, Municipais e do Distrito Federal (DF). A elaboração dos Planos Estaduais, Municipais e do DF é de responsabilidade de seus gestores, entretanto, deve ser estimulado e realizado o diálogo com a população e com movimentos sociais, para que haja a discussão pública durante a elaboração do mesmo, havendo assim, maior democracia e participação nas decisões tomadas, o que facilitará e dará impulso no momento em que o mesmo será executado.

\section{Sistema Nacional de Habitação de Interesse Social (SNHIS)}

Como um dos subsistemas do Sistema Nacional de Habitação, o Sistema Nacional de Habitação de Interesse Social (SNHIS) se destaca como sendo resultante de um Projeto de Lei de iniciativa popular apresentado ao Congresso Nacional em 1991. Esse foi o primeiro, e até então, o único Projeto de Lei fruto da mobilização nacional de movimentos sociais, sendo eles tanto dos Movimentos Populares de Moradia e do Movimento Nacional de Reforma Urbana. O Projeto esteve em tramitação no Congresso durante mais de 13 anos, quando foi finalmente aprovado e originou a Lei $\mathrm{n}^{\mathrm{o}} 11.124$, de 16 de Junho de 2005. A Lei dispõe sobre o Sistema 
Nacional de Habitação de Interesse Social, cria o Fundo Nacional de Habitação de Interesse Social (FNHIS) e institui, ainda, o Conselho Gestor do FNHIS.

Assim, o SNHIS tem papel fundamental, visto seu principal objetivo de garantir ações que visem a promoção do acesso à moradia digna para a população com menor renda. Além disso, objetiva ainda criar políticas e programas de investimentos e subsídios, que facilitem o acesso à habitação por parte da população de baixa renda, além de propor a articulação, compatibilização e acompanhamento de instituições que atuem no ramo da habitação, tal como se institui no artigo $2^{\circ}$ da Lei ${ }^{\circ} 11.124$ de 16 de Junho de 2005:

Art. $2^{\underline{ }}$ Fica instituído o Sistema Nacional de Habitação de Interesse Social SNHIS, com o objetivo de:

I - viabilizar para a população de menor renda o acesso à terra urbanizada e à habitação digna e sustentável;

II - implementar políticas e programas de investimentos e subsídios, promovendo e viabilizando o acesso à habitação voltada à população de menor renda; e

III - articular, compatibilizar, acompanhar e apoiar a atuação das instituições e órgãos que desempenham funções no setor da habitação.

Ainda com base no mesmo documento legal, tem-se definidas no artigo $4^{\circ}$, a estrutura, organização e atuação do SNHIS, que devem observar princípios e diretrizes, conforme descrito nos incisos I e II a seguir:

Art. 4ํำ A estruturação, a organização e a atuação do SNHIS devem observar: I - os seguintes princípios:

a) compatibilidade e integração das políticas habitacionais federal, estadual, do Distrito Federal e municipal, bem como das demais políticas setoriais de desenvolvimento urbano, ambientais e de inclusão social;

b) moradia digna como direito e vetor de inclusão social;

c) democratização, descentralização, controle social e transparência dos procedimentos decisórios;

d) função social da propriedade urbana visando a garantir atuação direcionada a coibir a especulação imobiliária e permitir o acesso à terra urbana e ao pleno desenvolvimento das funções sociais da cidade e da propriedade;

II - as seguintes diretrizes:

a) prioridade para planos, programas e projetos habitacionais para a população de menor renda, articulados no âmbito federal, estadual, do Distrito Federal e municipal;

b) utilização prioritária de incentivo ao aproveitamento de áreas dotadas de infra-estrutura não utilizadas ou subutilizadas, inseridas na malha urbana;

c) utilização prioritária de terrenos de propriedade do Poder Público para a implantação de projetos habitacionais de interesse social;

d) sustentabilidade econômica, financeira e social dos programas e projetos implementados;

e) incentivo à implementação dos diversos institutos jurídicos que regulamentam o acesso à moradia;

f) incentivo à pesquisa, incorporação de desenvolvimento tecnológico e de formas alternativas de produção habitacional; 
g) adoção de mecanismos de acompanhamento e avaliação e de indicadores de impacto social das políticas, planos e programas; e

h) estabelecer mecanismos de quotas para idosos, deficientes e famílias chefiadas por mulheres dentre o grupo identificado como o de menor renda da alínea "a" deste inciso.

Visto isso, salienta-se o papel desse Sistema em dar enfoque principal a implementação de políticas e programas visando acesso a moradia digna à população com menor renda, a qual representa quase a totalidade do déficit habitacional brasileiro, visto que, a PNH busca focar de forma mais geral o déficit habitacional, não sendo demasiadamente específica. Daí surge a necessidade desse Sistema, que centraliza todos os programas e projetos destinados a Habitação de Interesse Social. Segundo o modelo proposto para o SNHIS, o subsídio destinado às famílias deve ser inversamente proporcional a sua capacidade aquisitiva, ou seja, maiores subsídios às famílias de menor renda. Entretanto, para que isso seja cumprido efetivamente, deve-se salientar o trabalho articulado entre os gestores estaduais e municipais em consonância com o Governo Federal através do Ministério das Cidades, lembrando a necessidade de municípios, estados e o DF se responsabilizarem pela elaboração de planos de habitação de interesse social, através do qual o Ministério das Cidades terá a possibilidade de fazer análises e definir linhas de financiamento.

\section{Fundo Nacional de Habitação de Interesse Social (FNHIS)}

O Fundo Nacional de Habitação de Interesse Social (FNHIS), também criado segundo a Lei $n^{\circ} 11.124$ de 2005, tem caráter contábil, sendo o responsável por centralizar e gerenciar recursos provenientes de diversas fontes, com objetivo de servir à realização dos programas estruturados no âmbito do SNHIS, voltados especialmente à população de baixa renda. Além disso, o FNHIS desempenha importante função, servindo como instrumento de incentivo por parte do Governo Federal aos governos estaduais e municipais, para que esses componham seus fundos com o mesmo objetivo.

A composição do fundo se faz através de recursos originados de fontes como o Orçamento Geral da União (OGU); Fundo de Apoio ao Desenvolvimento Social (FAS); empréstimos internos e externos; contribuições e doações de pessoas físicas ou jurídicas; entidades e organismos de cooperação nacional ou internacional; receitas de operações realizadas com recursos do FNHIS. Todos os recursos obtidos através das fontes mencionadas, que possuem papeis diferenciados dentro do FNHIS, são aplicados de formas variadas, e de acordo com critérios já mencionados, como renda mensal familiar. Assim, é previsto em lei que tais recursos podem ser utilizados para aquisição, construção, conclusão, 
melhoria ou reforma de habitações, para que seja feita a regularização fundiária ou utilizado na infraestrutura, como saneamento básico, ou para a urbanização de assentamentos ou produção de equipamentos comunitários. Além disso, ainda é possível que os recursos sejam investidos na compra de terrenos ou em outras ações relacionadas à habitação, desde que esteja de acordo com o programa de habitação de interesse social estabelecido e vinculado à política de desenvolvimento urbano expressa no Plano Diretor Municipal.

\section{O Programa de Aceleração do Crescimento (PAC)}

O Programa de Aceleração do Crescimento (PAC) se constitui como um conjunto de políticas, diretrizes e ações econômicas estabelecidas pelo governo federal, com o intuito de promover o crescimento econômico de 5\% ao ano para o período 2007 a 2010, visto que estavam ausentes nas últimas décadas, propostas pautadas no desenvolvimento econômico do Brasil.

Neste sentido, os investimentos previstos neste programa organizam-se nas seguintes linhas: infraestrutura energética (geração e transmissão de energia elétrica, combustíveis renováveis, exploração e transporte de petróleo); infraestrutura logística (construção e ampliação de rodovias, hidrovias, ferrovias, portos, aeroportos) e infraestrutura social e urbana (investimento no saneamento, trens urbanos, habitação e popularização do programa "Luz para Todos").

Para a efetivação das metas do PAC, estão previstos investimentos da ordem de R\$ 503,9 bilhões de reais até o ano de 2010, sendo que deste total cerca R\$170,8 bilhões serão direcionados para infraestrutura urbana, R \$ 106,3 bilhõs para habitação e R \$ 12 bilhões para a urbanização de favelas. Destes recursos destinados para a habitação, cerca de R\$10,1 bilhões são provenientes do Orçamento Geral da União. Notadamente, os projeto PAC Urbanização de favelas visa, sobretudo, despoluir mananciais, erradicar palafitas, e equacionar áreas de risco (desmoronamento, inundações e violência) nas grandes cidades brasileiras, tendo em vista que existem favelas nas capitais brasileiras habitadas por cerca de 20 mil famílias, que terão $25 \%$ dos moradores beneficiados pelas obras do PAC. (Governo Federal do Brasil PAC, 2009)

A definição do direcionamento de recursos planejados para o Programa Prioritário de Investimento (PPI/PAC), com o intuito de determinar as prioridades de atendimento ocorreu com a participação dos representantes dos 26 Estados e Distrito Federal, das capitais e municípios com mais de 150 mil habitantes e dos municípios de doze Regiões Metropolitanas. Em relação aos pré-requisitos para seleção de projetos de urbanização de favelas, destacam- 
se: a prevenção/mitigação do impacto de grandes instalações de infraestrutura nacional; a recuperação ambiental; a eliminação de gargalos da infraestrutura logística (ocupações em áreas de aeroportos, portos e ferrovias) e projetos de grande porte com impacto na articulação e integração do território. Além disso, estes projetos devem apresentar legalidade fundiária das regiões que serão beneficiadas e licença ambiental prévia. A princípio, foram realizadas reuniões com governadores e prefeitos, quando cada unidade federativa poderia apresentar novos projetos a serem discutidos na segunda etapa das reuniões. Posteriormente, na segunda etapa, foram apresentadas as características mais específicas, sendo que estas reuniões ocorriam em grupos menores e as discussões pautavam-se nos detalhes técnicos dos projetos e na população a ser beneficiada pelos mesmos. Cabe ressaltar que estas reuniões foram conduzidas pela Ministra Chefe da Casa da Presidência da República Dilma Russef, e com a colaboração do Ministério das Cidades, Secretaria Nacional de Habitação e Saneamento Ambiental e Ministério do Planejamento e Orçamento.

\section{Considerações Finais}

Ao longo de seu processo histórico, o Estado brasileiro buscou alterar suas concepções e modelos de intervenção por meio de políticas públicas nacionais, e no que tange às questões habitacionais, notadamente à moradia para a população de baixa renda. Porém, ainda que hajam tais intervenções por parte dos governantes, constata-se a partir dos dados da Secretaria Nacional de Habitação, que o déficit habitacional no Brasil ainda é muito elevado, atingindo o valor de 7,2 milhões de moradias, sendo que somente na cidade de São Paulo existem cerca de 5,5 milhões de habitações irregulares. Neste cenário, confirma-se que 17\% dos domicílios do país são alugados, e cerca de $80 \%$ das moradias resultam da autoconstrução, prática comum das famílias desprovidas de renda que reaproveitam materiais de construção já descartados, e que contam com a colaboração de mutirões de suas comunidades como oferta de mão-de-obra.

Em contrapartida, nas áreas metropolitanas da região Sudeste encontram-se imóveis vagos em número superior as necessidades habitacionais identificadas. Outra contradição refere-se ao superávit da construção civil, já que seu valor total corresponde a 8,5\% do PIB brasileiro, ou seja, resultado que manifesta um dos setores mais promissores para investimentos do segmento empresarial, o qual é responsável pelo emprego de 8,2 milhões de trabalhadores.

Em concordância com o Fórum Nacional de Reforma Urbana, o problema da questão habitacional no Brasil não se resolverá apenas com a ampliação de recursos, mas sim, com a 
efetiva regularização da posse de ocupações, e ainda, com a destinação de medidas e de recursos do governo federal para a ocupação de imóveis vazios das áreas centrais, que podem ser designados para a habitação de interesse social. Há também a problemática referente à ausência de discussões e assembléias que debatam a destinação dos recursos, uma vez que os investimentos para habitação foram determinados sem o parecer do Conselho Nacional das Cidades, por Conselhos Gestores dos Fundos financiadores, e sem a consulta à sociedade civil.

Entretanto, apesar das falhas levantadas e dos problemas a serem solucionados pelos atuais e futuros governantes do país, vale ressaltar que na administração do presidente Luís Inácio Lula da Silva houveram ações positivas em prol da questão habitacional, visto que, desde o ano de 1986 permaneceram ausentes propostas e planejamentos adequados às populações menos favorecidas. Assim, entre avanços e recuos da problemática habitacional, foram criados no atual governo: o Ministério das Cidades, o SNH, o SNHIS e FNHIS e uma $\mathrm{PNH}$, o que demonstra o interesse do governo em apresentar uma política mais ajustada às deficiências habitacionais do território. No entanto, o grande desafio da atual gestão presidencial, unidades federativas e municípios, tangem a aplicação devida dos recursos, garantindo e fiscalizando a operacionalização destes instrumentos criados. Há também os desafios de reduzir desigualdades sociais, as quais são duramente denunciadas pelos dados, bem como contribuir para a melhor distribuição da população, uma vez que existe um alto contingente populacional sem moradia digna, num país de grande extensão territorial.

\section{Referências}

Instituto Brasileiro de Geografia e Estatística - IBGE. Disponível em: <www.ibge.gov.br>. Acesso em Maio de 2009.

Instituto Polis. Fórum Nacional de Reforma Urbana denuncia investimentos do PAC não garantem direito a moradia digna. Disponível em: <campaign.hic-net.org $>$. Acesso em Maio de 2009.

MAGALHÃES, I.; BLANCO Jr, C. A política nacional de habitação e os processos de coordenação federativa para atendimento da população moradora de favelas. In: XIII Congreso Internacional del CLAD sobre la Reforma del Estado y de la Administración Pública. Buenos Aires, Argentina, 4 - 7 nov. 2008.

MARICATO, E. A Nova Política Nacional de Habitação. [s.n.d].

Ministério das Cidades. Política Nacional de Habitação. Brasília, 2004. 
Programa de Aceleração do Crescimento - PAC. Disponível em: $<$ https://www.pac.gov.br/>. Acesso em Maio de 2009.

República Federativa do Brasil. Portal do Governo Brasileiro. Programa de Aceleração do Crescimento. Disponível em: <http://www.brasil.gov.br/pac/>. Acesso em Maio de 2009.

Secretaria Nacional de Habitação. Plano Nacional de Habitação. Disponível em: $<: / /$ www.cidades.gov.br/secretarias-nacionais/secretaria-de-habitacao/planhab $>$. Acesso em Maio de 2009.

Secretaria Nacional de Programas Urbanos. Terra Urbanizada para Todos. Disponível em: $<$ www.cidades.gov.br/secretarias-nacionais/programas-urbanos $>$. Acesso em Maio de 2009. 